\title{
Research on The Effect of Subject Heterogeneity on Innovation Performance in Manufacturing Digital Innovation
}

\author{
Jing Gao ${ }^{1}$, Wanfei Zhan ${ }^{1}$, Tao Guan ${ }^{2,}$, and Qiuhong Feng ${ }^{1}$ \\ ${ }^{1}$ School of Economics and Management Harbin University of Science and Technology Harbin, China \\ ${ }^{2}$ School of Economics and Management Harbin Institute of Technology Harbin, China
}

\begin{abstract}
The digital transformation of manufacturing industry accelerates the collaborative innovation of multi-agent value co-creation, which makes the influence of subject heterogeneity on the innovation performance in digital innovation become a focus issue in both theory and practice. This paper builds a conceptual model of subject heterogeneity in digital collaborative innovation influence on the innovation performance from target heterogeneity, knowledge heterogeneity and organization heterogeneity three dimensions, which based on the perspective of the behavior subjects in manufacturing digital innovation of value co-creation. Then we deeply explore the influence mechanism between the heterogeneous cooperative innovation behavior of heterogeneous value subject and the innovation performance in digital innovation. The research results are helpful to realize higher quality digital cooperation among manufacturing enterprises, promote the coordinated development of digital value chain, and improve the digital innovation performance.
\end{abstract}

\section{INTRODUCTION}

With the development of digital technology, the digital innovation has become a new trend. The digital transformation of manufacturing industry accelerated the formation of digital innovation ecosystem, which changes the model from a single enterprise itself circulation to the collaborative innovation of multi-subject network on manufacturing value chain. The new innovation model not only changes the enterprises' business model, but also changes the development model in the whole manufacturing industry. The value co-creation has become the major innovation activities in the value chain of total factor convergence ${ }^{[1]}$. It is helpful to improve the enterprise innovation performance that establishs close cooperation and interaction between different subjects ${ }^{[2]}$. At present, the relevant researches on digital innovation performance are mainly analyzed from the external factors such as digital transformation ${ }^{[3][4]}$, digital level ${ }^{[5][7]}$, government policy ${ }^{[8]}$, which rarely involves the analysis of the different subjects in digital innovation. Heterogeneity of the innovation subjects provides the lacked key resources of enterprises, improves the cooperation intensity between enterprises, and provides enterprises with different knowledge and technology, but it may increase a certain innovation risk and $\operatorname{cost}^{[9]}$. Therefore, this paper analyzes the concept and dimensions of manufacturing subject heterogeneity in digital innovation, which is based on the perspective of the behavior agents in manufacturing digital innovation of value co-creation, then studies the influencing mechanism of subject heterogeneity of digital innovation performance. This research reveals the internal relations between the heterogeneous cooperative innovation behavior of heterogeneous value subject and the innovation performance in digital innovation. It promotes the value co-creation of manufacturing enterprises, accelerates the coordinated development of digital innovation, and presents implications of improving the innovation performance for enterprises.

\section{CONCEPT AND DIMENSIONS OF SUB- JECT HETEROGENEITY}

\subsection{Concept Definition of Subject Heterogeneity}

The concept of subject heterogeneity originates from partner heterogeneity, which was mainly studied partners in alliances and innovation networks initially. Parkhe (1991) put forward the concept of partner heterogeneity for the first time at the end of the 20th century, arguing that the effect of the enterprises' strategic alliance is due to the heterogeneity among different enterprises and the existence of differentiation (such as complementary resources and different cooperation motivations) ${ }^{[10]}$. Beckman and Haunschild (2002) summarized the subject heterogeneity in the innovation network as the diversity of subject experience ${ }^{[11]}$. Subsequently, many scholars have studied the heterogeneity of partners from the perspectives of complementarity and diversity of knowledge and resources, and pointed out that heterogeneity is the transfer of knowledge, technology and resources across organizational boundaries. Such as Liang Liang (2014), based on the theory of resource view, summarized the

\footnotetext{
* Corresponding author: hitguantao@163.com
} 
heterogeneity of partners as the heterogeneity of various resources, that is, the degree of differentiation and diversification of multiple organizations in knowledge, technology, ability and other resources ${ }^{[12]}$.

The development of digital technology accelerates the digital transformation of manufacturing enterprises, and triggers the transformation of innovation concept, innovation environment, innovation mode, innovation organization and innovation activities. Enterprise digital transformation refers to the transformation of strategic behavior in which enterprises introduce digital technology to realize the digitalization of production, management and sales at all levels, enhance the core competitiveness and realize short-term and long-term profit appreciation. On this basis, the value chain formed by the convergence of various subjects and factors becomes the main position of digital innovation in the manufacturing industry. In this value chain, all subjects play different roles and jointly provide customers with a complete set of products or solutions. In view of this, this paper mainly analyzes the heterogeneity of enterprises in the manufacturing digital innovation vertical value chain, that is, the diversity of different enterprises in the aspects of target, technology, market, organization, etc.

\subsection{Dimensions of Subject Heterogeneity}

At present, the dimensions of subject heterogeneity are mainly divided into four aspects, as shown in Table 1:

Table 1 the dimensions of subject heterogeneity

\begin{tabular}{|c|c|c|}
\hline perspective & dimensions & scholars \\
\hline $\begin{array}{l}\text { Innovation } \\
\text { alliance }\end{array}$ & $\begin{array}{l}\text { complementarity, equilibrium } \\
\text { and mutual exclusiveness }\end{array}$ & $\begin{array}{c}\text { Liufang } \\
\text { Yu }^{[13]} \text { etc. } \\
(2017)\end{array}$ \\
\hline \multirow{2}{*}{$\begin{array}{l}\text { Innovation } \\
\text { Networks }\end{array}$} & $\begin{array}{c}\text { target heterogeneity, cultural } \\
\text { heterogeneity and management } \\
\text { autonomy heterogeneity }\end{array}$ & $\begin{array}{l}\text { Guanju } \\
\text { Chen }{ }^{[17]} \\
\text { etc. }(2020) \\
\end{array}$ \\
\hline & $\begin{array}{l}\text { resource heterogeneity of } \\
\text { organization and relationship }\end{array}$ & $\begin{array}{l}\text { Xinghua } \\
\text { Dang }{ }^{[14]} \\
\text { etc. }(2010)\end{array}$ \\
\hline \multirow{2}{*}{$\begin{array}{l}\text { Industry } \\
\text { University } \\
\text { Research } \\
\text { Cooperation }\end{array}$} & $\begin{array}{l}\text { organizational differences, } \\
\text { target differences and resource } \\
\text { differences }\end{array}$ & $\begin{array}{c}\text { Xuejiao } \\
\mathrm{Li}^{[9]}(2019)\end{array}$ \\
\hline & $\begin{array}{l}\text { knowledge heterogeneity, } \\
\text { relationship heterogeneity and } \\
\text { concept heterogeneity }\end{array}$ & $\begin{array}{c}\text { Yong } \\
\text { Dai }{ }^{[16]} \text { etc. } \\
(2016) \\
\end{array}$ \\
\hline \multirow{2}{*}{$\begin{array}{c}\text { open } \\
\text { innovation }\end{array}$} & $\begin{array}{c}\text { organizational heterogeneity, } \\
\text { industrial heterogeneity and } \\
\text { national heterogeneity }\end{array}$ & $\begin{array}{c}\text { Liang } \\
\text { Liang }{ }^{[12]} \\
(2014) \\
\end{array}$ \\
\hline & $\begin{array}{c}\text { differences in organizational } \\
\text { types, technical capabilities and } \\
\text { targets }\end{array}$ & $\begin{array}{c}\mathrm{Hu} \\
\text { Yue }^{[21]} \text { etc. } \\
(2018)\end{array}$ \\
\hline
\end{tabular}

According to the above classification of subject heterogeneity and combining with the characteristics of digital innovation in manufacturing industry, subject heterogeneity is summarized into three dimensions: target heterogeneity, knowledge heterogeneity and organization heterogeneity in this paper.

\subsubsection{Target Heterogeneity}

Target heterogeneity means that the innovation subjects in manufacturing value chain pursue different goals. The reasons that lead to the difference of the subject target are as follows: On the one hand, in manufacturing value chain, due to the different division of labor and innovation stage in the value chain, each enterprise has different business philosophy, development background and resource allocation ${ }^{[17]}$. On the other hand, enterprises can obtain diversified resources through cooperation and interaction with other subjects, but each subject has the different emphasis on the acquisition and use of resources, thus forming different development goals ${ }^{[17]}$. In addition, the diversity of business philosophy and corporate culture of the innovation subjects also makes the subjects present the characteristic of target heterogeneity.

\subsubsection{Knowledge Heterogeneity}

Knowledge heterogeneity refers to the fact that the subject has different knowledge due to different resources. Enterprises collect innovative knowledge sources through the value chain and convert them into innovative achievements according to their goals and needs. In the process of realizing innovation value, different subjects occupy different innovation resources due to their different positions and roles in the value chain, which leads to the formation of differentiated capabilities among subjects and knowledge heterogeneity. Knowledge heterogeneity can be divided into two aspects: technical knowledge heterogeneity and market knowledge heterogeneity ${ }^{[19]}$.On the one hand, the application of digital technology is indispensable in digital innovation. In the process of digital transformation, enterprises have learned and accumulated a certain amount of digital technology and will continue to learn new digital technology for innovation. The digital technology is the basis for manufacturing new products ${ }^{[20]}$. On the other hand, due to the personalized characteristics of digital achievements, different enterprises will have different user feedback information and business information from different customers, resulting in the diversification of market knowledge.

\subsubsection{Organization Heterogeneity}

Organization heterogeneity refers to the difference and diversity among enterprises in terms of age, size, organizational structure, operation mode, degree of digitalization, etc. There are three main reasons for organizational heterogeneity. First, there are many enterprises of different ages and sizes in the manufacturing industry, and they occupy different positions in the industry or value chain. Secondly, due to the heterogeneity of enterprises' target and knowledge, enterprises have formed their own unique management mode in the process of production and operation, showing different organizational structures and operation modes ${ }^{[21]}$. Third, the digital transformation of manufacturing has become a necessary option for the development of enterprises under the background of digital innovation, difference of digital degree also make enterprises show organization heterogeneity. For example, some enterprises have completed the digital transformation, realized the digital 
production processes and business models, some enterprises only introduced some digital products, business model has not been digitally shift, etc.

\section{RESEARCH MODEL AND HYPOTHE- SIS DEVELOPMENT}

\subsection{Research Model on Digital Innovation Performance}

In digital innovation, the innovation process is based on the value chain, more innovation main body through multiple stages of development for lots of input and output. Heterogeneity of the innovation subjects provide the lacked key resources of enterprises, improve cooperation intensity between enterprises, and provide enterprises with different knowledge and technology, but it may increase a certain innovation risk and cost, which affects digital innovation innovation performance on each section of the value chain. According to the concept and dimensions of subject heterogeneity, we use digital strategy target and product concept to measure target heterogeneity, with the difference and diversity of technical knowledge and market knowledge to measure knowledge heterogeneity, with the difference of digital degree and organization size of partners to measure organization heterogeneity, to analyze its effects on digital innovation performance.

In addition, in digital innovation, the production mode of manufacturing enterprises changes from the production of single products to customer-centered customized mass production, which promotes the cross-field and multisubject collaborative development to become the main mode of innovation. Therefore, the collaborative innovation behavior of various innovation subjects in digital cooperation also has a certain impact on the innovation performance of enterprises. Close communication and complementary knowledge and ability in the cooperation process are conducive to improving the digital innovation performance of various innovation subjects. At the same time, high-quality cooperation cannot be separated from cooperative objects with high fitness degree. Subject heterogeneity will inevitably have a certain impact on cooperation between subjects and even innovation performance. In this paper, cooperation intensity refers to the closeness of cooperation and communication among various subjects, and interaction frequency and cooperation quality are used to measure the cooperation intensity. Interaction frequency refers to the frequency of communication between subjects in the process of cooperation. Communication between subjects can be divided into formal interaction and informal interaction. The improvement of cooperation quality can promote the deep cooperation between heterogeneous subjects, and emphasize the stability and results in the digital cooperation. Referred to other scholars' research on cooperation quality, we measure cooperation quality from four aspects: cooperation time, cooperation trust, cooperation satisfaction, and cooperation effect. Therefore, we establishe the following research model, then quantitatively study the relationship among variables according to the model.

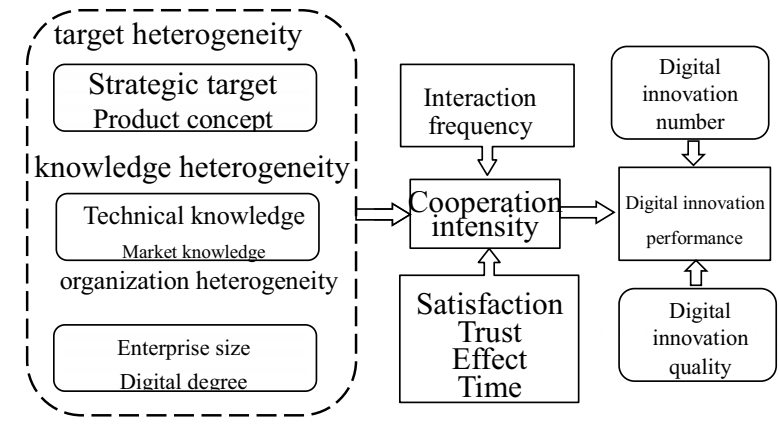

Figure 1 Research model

\subsection{Hypotheses}

\subsubsection{Effects of Target Heterogeneity on Digital Innovation Performance}

In digital innovation, due to the dynamic and flexible characteristics of digital products, the production process is usually not completed by a single enterprise independently. It requires collaborative innovation by multiple different knowledge subjects in the value chain, and provides innovation products meeting the personalized needs of customers. At this time, different enterprise targets will make enterprises obtain different resources from the digital platform or cooperation, and in order to achieve the enterprise targets, the limited resources will be mainly used for the development of important projects, which will cause the resource limitation of secondary projects, and then affect the innovation performance of the project. On the other hand, in the multi-subject digital cooperation, due to the different targets of the innovation subjects, the failure of timely communication and mutual support in terms of strategic targets and product concepts will inevitably affect the innovation process and product development, then negatively affecting the innovation performance. Therefore, this paper believes that the target heterogeneity will have a negative impact on innovation performance, and puts forward the following hypothesis:

H1: Target heterogeneity relates negatively to digital innovation performance.

Knowledge is the core element of innovation. If enterprises want to build their long-term competitive advantage through innovation, they must pay attention to the acquisition and utilization of external heterogeneous knowledge resources. Technology innovation is the important driving force in the process of digital innovation. Enterprises can learn and get more digital technologies through technical knowledge heterogeneity, and introduce them in the process of design, development and manufacture, to realize intelligent industrial chain, collaborative interactive integration of production, so that the production process can realize digital to increase production efficiency ${ }^{[22]}$. At the same time, enterprises obtain market information through the market knowledge heterogeneity and make full use of big data to accurately grasp customer needs. This is conducive to the rapid updating and iteration of enterprises' digital achievements and innovative products and the improvement of product 
quality. However, when enterprises face the heterogeneity of technology and market knowledge, too much it will cause information overload phenomenon when enterprises face too much technology and market knowledge. Especially in the era of big data, the enterprise needs to put in more resources to identify and absorb amounts of data and technology, resulting in a decline in the efficiency of information processing, causes the negative effect of knowledge sharing, at the same time produces more operating cost. Therefore, this paper holds that there is a nonlinear relationship between knowledge heterogeneity and digital innovation performance, and puts forward the following hypothesis:

$\mathrm{H} 2$ : Knowledge heterogeneity has an inverted Ushaped relationship with digital innovation performance.

Organization heterogeneity provides enterprises with more available resources and technologies. The difference of organizational types can improve the targeted acquisition and utilization of innovation resources. The more diversified organizational types of enterprise cooperation, the more conducive to the improvement of enterprise innovation performance. Especially for enterprises that have not completed the digital transformation, cooperation with subjects with high digital degree is conducive to obtaining digital resources and technologies, helping enterprises realize digital production, accelerating the digital transformation of enterprises and improving innovation performance. However, it should be noted that the more heterogeneous organizations in the process of enterprise cooperation, the higher the management cost of the enterprise. When enterprises of different enterprise size and degree of digitalization cooperate, it is easy for small enterprises to steal digital technology and free ride in order to realize digital transformation. This will lead to the failure of cooperation and make the core technology or resources of the enterprise leak, and it is necessary to take certain cooperation risks. Therefore, this paper holds that there is a nonlinear relationship between organization heterogeneity and digital innovation performance, and puts forward the following hypothesis:

H3: Organization heterogeneity has an inverted Ushaped relationship with digital innovation performance.

\subsubsection{Mediating Effect of Cooperation Intensity}

Due to the heterogeneity of target, knowledge and organization between enterprises and partners, subjects begin to pay attention to exchange and interaction in the process of cooperation. Therefore, enterprises will maintain close contact and communication with partners to ensure the smooth progress of cooperation. In view of subject heterogeneity and interaction frequency, this paper puts forward the following hypotheses:

H4: Target heterogeneity relates positively to interaction frequency.

H5: Knowledge heterogeneity relates positively to interaction frequency.

H6: Organization heterogeneity relates positively to interaction frequency.

The increase of interaction frequency can increase the mutual familiarity between enterprises, clarify the needs of each other, and improve the efficiency of cooperation. Increasing the number of exchanges and interactions can enable enterprises to understand each other's business models and corporate cultures, integrate and coordinate different targets, and reduce the occurrence of cooperative conflicts $^{[23]}$. In addition, due to the rapid update of information and products in the digital era, increasing interaction frequency can enable enterprises to quickly acquire new resources and technologies from each other, achieve the purpose of rapid exchange and learning of new knowledge, obtain diversified information and improve innovation performance. Multiple interactions during the cooperation can also enable the subjects to understand each other's work progress, optimize the organizational structure and management mode of the enterprise in a timely manner, achieve a win-win situation, promote the advancement of the digital process, and obtain better cooperation results. Therefore, we propose the following hypothesis:

H7: Interaction frequency relates positively to digital innovation performance.

When the target heterogeneity of the subject is too incompatible, there may be some misunderstanding in the process of cooperation, which will affect the cooperation relationship. Moreover, there will be some enterprises damage the collective interests in order to achieve their own targets and deviate from the cooperation. This will lead to the reduction of the trust of the partners, which will lead to the reduction of the cooperation quality. The knowledge heterogeneity is conducive to the partners' rapid access to the latest market information and digital technology, grasp of customer needs timely, product upgrading and upgrading, keeping up with the pace of market changes in the digital era, and ensuring the market frontier of innovative products. Different organizational structures and digitalization degrees of each subject bring diversity to the cooperation mode, but such cooperation requires a high degree of trust among the subjects. When the degree of organization heterogeneity increases, it means that the risk of cooperation will also increase. Therefore, we can put forward the following hypotheses:

H8: Target heterogeneity relates negatively to cooperation quality.

H9: Knowledge heterogeneity relates positively to cooperation quality.

H10: Organization heterogeneity relates positively to cooperation quality.

In the process of cooperation, the establishment of long-term cooperative relationship is conducive to the deep exchange and absorption of resources and technologies among various subjects, and reduces the time to adapt to each other's targets and improves the innovation performance. In digital innovation, digital technology is the driving force and core, and the improvement of cooperation stability and cooperation trust is conducive to reducing free-riding phenomenon and opportunistic behavior, making the cooperation between subjects smooth and reducing cooperation risks. The contribution and effect brought by cooperation are the results produced by cooperation, which directly reflect the impact on innovation performance. The better the 
cooperation effect, the higher the innovation performance. Therefore, we can put forward the hypothesis:

H11: Cooperation quality relates positively to digital innovation performance.

\section{RESEARCH DESIGN AND DATA COLLECTION}

\subsection{Survey Questionnaire Design and Measure- ment}

On the basis of the conceptual model and research hypothesis mentioned above, this paper refers to the previous survey questionnaire design, and combines the research content of this research to determine the survey items of this paper. The survey questionnaire is mainly divided into two parts. The first part is the basic information of the respondents. The second part is the questionnaire measurement. Those involved in the research model were measured on a 5-point Likert type scale using multiple items, where a response of " 1 " indicated "strongly disagree" and "5" indicated "strongly agree". SPSS 24.0 statistical software is used to analyze the data. Specific measurement items are shown in the following table.

Table 2 Variable scale

\begin{tabular}{|c|c|c|c|}
\hline Variable & Dimension & Observed variable & scholar \\
\hline \multirow{10}{*}{$\begin{array}{l}\text { Explanatory } \\
\text { variable }\end{array}$} & \multirow{4}{*}{$\begin{array}{c}\text { Target } \\
\text { heterogeneity } \\
\left(\mathrm{X}_{1}\right)\end{array}$} & $\begin{array}{l}\mathrm{x}_{11} \text { : There are big differences between us and our partners in achieving the } \\
\text { strategic goals of digitization }\end{array}$ & \multirow{4}{*}{$\begin{array}{l}\mathrm{Hu} \\
\text { Yue }^{[21]} \text { Zhaoyun } \\
\text { Wang }^{[24]}\end{array}$} \\
\hline & & $\begin{array}{l}\mathrm{x}_{12} \text { : There are big differences between us and our partners in the concept of digital } \\
\text { products. }\end{array}$ & \\
\hline & & $\mathrm{x}_{13:}$ The targets of our cooperation are not compatible with our partners. & \\
\hline & & $\mathrm{X}_{14}$ We support each other's goals in the digital cooperation. & \\
\hline & \multirow{3}{*}{$\begin{array}{l}\text { Knowledge } \\
\text { heterogeneity } \\
\left(\mathrm{X}_{2}\right)\end{array}$} & $\begin{array}{l}\mathrm{x}_{21:} \text { There are big differences between us and our partners in knowledge, } \\
\text { technology and innovation capabilities }\end{array}$ & \multirow{3}{*}{$\begin{array}{l}\text { Qiang } \\
\text { Cheng }{ }^{[25]} \text { etc. }\end{array}$} \\
\hline & & $\begin{array}{l}\mathrm{x}_{22} \text { : We have difficulty fully absorbing and digesting the knowledge transfer of } \\
\text { our partners }\end{array}$ & \\
\hline & & $\mathrm{x}_{23}$ : Our knowledge is effectively complementary to our patners'. & \\
\hline & \multirow{3}{*}{$\begin{array}{l}\text { Organization } \\
\text { heterogeneity } \\
\qquad\left(\mathrm{X}_{3}\right)\end{array}$} & $\begin{array}{l}\mathrm{x}_{31} \text { : There are big differences between us and our partners in the degree of } \\
\text { digitization }\end{array}$ & \multirow{3}{*}{$\begin{array}{l}\text { Yuanyuan } \\
\text { Jiao }^{[15]}, \text { Beibei } \\
\text { Zhao }^{[18]} \text { etc. }\end{array}$} \\
\hline & & $\begin{array}{l}\mathrm{x}_{32} \text { : There are big differences between us and our partners in enterprise size, age, } \\
\text { organizational structure. }\end{array}$ & \\
\hline & & $\begin{array}{l}\mathrm{x}_{33} \text { There are big differences between us and our partners in Professional division } \\
\text { of labor in the value chain. }\end{array}$ & \\
\hline \multirow{7}{*}{$\begin{array}{l}\text { Intervening } \\
\text { variable }\end{array}$} & \multirow{3}{*}{$\begin{array}{l}\text { Interaction } \\
\text { frequency } \\
\left(\mathrm{Y}_{1}\right)\end{array}$} & $\mathrm{y}_{11:}$ We have regular formal communication and reports with our partners. & \multirow{3}{*}{$\begin{array}{l}\text { Lisheng Wang }{ }^{[26]} \\
\text { etc. }\end{array}$} \\
\hline & & $\mathrm{y}_{12}$ : We and our partners send people to each other on a regular basis. & \\
\hline & & $\mathrm{y}_{13:}$ We often solve problems encountered in cooperation with our partners. & \\
\hline & \multirow{4}{*}{$\begin{array}{l}\text { Cooperation } \\
\text { quality } \\
\left(\mathrm{Y}_{2}\right)\end{array}$} & $\mathrm{y}_{21}$ Both of us and our partners are satisfied with the cooperation. & \multirow{4}{*}{ Jing Song ${ }^{[27]}$ etc. } \\
\hline & & $\begin{array}{l}y_{22} \text { : Both of us and our partners are willing to maintain a long-term cooperative } \\
\text { relationship. }\end{array}$ & \\
\hline & & $\begin{array}{l}y_{23} \text { : We can have deep discussions with partners on cooperation contents and } \\
\text { share technologies and resources. }\end{array}$ & \\
\hline & & $\begin{array}{l}y_{24} \text { We have enhanced our digital innovation capability and obtained unexpected } \\
\text { benefits from the cooperation. }\end{array}$ & \\
\hline \multirow{5}{*}{$\begin{array}{l}\text { Explained } \\
\text { variable }\end{array}$} & \multirow{5}{*}{$\begin{array}{c}\text { Digital } \\
\text { innovation } \\
\text { performance } \\
\left(\mathrm{Y}_{3}\right)\end{array}$} & $\mathrm{y}_{31:}$ Our company has accelerated the development of new digital products. & \multirow{5}{*}{$\begin{array}{l}\text { Liang } \\
\text { Liang }^{[12]}, \text { Yongqia } \\
\text { ng Ma }{ }^{[28]} \text { etc. }\end{array}$} \\
\hline & & $\mathrm{y}_{32:}$ Our company has accelerated the digital technology upgrade speed. & \\
\hline & & $\mathrm{y}_{33:}$ The number of our company digital patents has increased. & \\
\hline & & $\mathrm{y}_{34:}$ The success rate of our company digital innovation projects has increased. & \\
\hline & & $\begin{array}{l}\mathrm{y}_{35} \text { : The proportion of our company digital product sales revenue in the total sales } \\
\text { has increased. }\end{array}$ & \\
\hline
\end{tabular}

\subsection{Sample and Data Collection}

The sample objects of this study are part of the manufacturing enterprises that have begun to digitize in China, mainly in the Yangtze River Delta region. Questionnaires were mainly distributed in several ways: First, 400 questionnaires were sent out through E-mail and online questionnaires, 232 were recovered and 206 were valid with an effective recovery rate of $51.5 \%$. Second, 12 questionnaires were sent out in offline and telephone interviews, 9 were received back and 8 were effective with an effective recovery rate of $66.6 \%$. A total of 412 questionnaires were sent out and 214 valid questionnaires were collected, with an effective rate of $51.9 \%$. The sample size is more than 200 , which satisfies the sample size requirement of SEM.
Most of the enterprises surveyed are in light textile manufacturing industry, accounting for $41.5 \%$, followed by electronics or machinery manufacturing industry are accounting for $34.6 \%$. And the resource processing manufacturing industry and equipment manufacturing industry, accounting for $23.9 \%$. From the perspective of the degree of enterprise digitalization, most manufacturing enterprises are in the stage of digital transformation, and the enterprises that have completed the digital transformation account for about $11.5 \%$. These enterprises have an important influence and lead role in the value chain of manufacturing digitalization, and have the most abundant digital resources and technologies. 


\subsection{Validity and Reliability}

\subsubsection{Validity}

In this paper, the Alpha reliability coefficient and CITC of target heterogeneity, knowledge heterogeneity, organization heterogeneity, interaction frequency, cooperation intensity and digital innovation performance were investigated by SPSS24.0 software. According to the measurement results (Table 3), the Cronbach $\alpha$ of all the above dimensional variables is greater than 0.7 , and the CITC of all the measured variables is greater than 0.35. In addition, the Cronbach $\alpha$ after the deletion of an item is all smaller than the Cronbach $\alpha$ before the deletion. Therefore, the scale has good internal consistency and reliability.

\subsubsection{Reliability}

According to the results (table 3), KMO test produced for each subscales is above 0.7 respectively, Bartlett inspection $\mathrm{P}$ values are 0 , show the strong correlation between each index, and next we can do exploratory factor analysis of the series of indicators. The number of factors produced Principal component analysis with varimax rotation is consistent with the above analysis, and factor loading of each measurement variables were greater than0.6. These show that the construct validity of the questionnaire in scale, so the validity of the content of the questionnaire design is reasonable and reliable.

Table 3 Results of validity and reliability testing

\begin{tabular}{|c|c|c|c|c|c|}
\hline Dimension & $\begin{array}{c}\text { Serial } \\
\text { number }\end{array}$ & CITC & $\begin{array}{l}\text { Cron } \\
\text { bach } \\
\text { ' } \alpha\end{array}$ & $\begin{array}{c}\text { loadi } \\
\text { ngs }\end{array}$ & $\mathrm{KMO}$ \\
\hline \multirow{4}{*}{$\begin{array}{l}\text { Target } \\
\text { heterogeneity } \\
\left(\mathrm{X}_{1}\right)\end{array}$} & $\mathrm{X}_{11}$ & .830 & \multirow{4}{*}{$\begin{array}{c}0.91 \\
7\end{array}$} & .887 & \multirow{10}{*}{.869} \\
\hline & $\mathrm{X}_{12}$ & .790 & & .852 & \\
\hline & $\mathrm{X}_{13}$ & .801 & & .862 & \\
\hline & $\mathrm{X}_{14}$ & .816 & & .890 & \\
\hline \multirow{3}{*}{$\begin{array}{l}\text { Knowledge } \\
\text { heterogeneity } \\
\left(\mathrm{X}_{2}\right)\end{array}$} & $\mathrm{X}_{21}$ & .679 & \multirow{3}{*}{$\begin{array}{c}0.82 \\
4\end{array}$} & .741 & \\
\hline & $\mathrm{X}_{22}$ & .664 & & .847 & \\
\hline & $\mathrm{X}_{23}$ & .694 & & .818 & \\
\hline \multirow{3}{*}{$\begin{array}{l}\text { organization } \\
\text { heterogeneity } \\
\left(\mathrm{X}_{3}\right)\end{array}$} & $\mathrm{X}_{31}$ & .731 & \multirow{3}{*}{$\begin{array}{c}0.85 \\
5\end{array}$} & .880 & \\
\hline & $\mathrm{X}_{32}$ & .731 & & .826 & \\
\hline & $\mathrm{X}_{33}$ & .724 & & .811 & \\
\hline \multirow{3}{*}{$\begin{array}{l}\text { interaction } \\
\text { frequency } \\
\left(Y_{1}\right) \\
\end{array}$} & $\mathrm{y}_{11}$ & .699 & \multirow{3}{*}{$\begin{array}{c}0.82 \\
9\end{array}$} & .824 & \multirow{7}{*}{.847} \\
\hline & $\mathrm{y}_{12}$ & .681 & & .850 & \\
\hline & $\mathrm{y}_{13}$ & .686 & & .837 & \\
\hline \multirow{4}{*}{$\begin{array}{l}\text { cooperation } \\
\text { quality }\left(\mathrm{Y}_{2}\right)\end{array}$} & $\mathrm{y}_{21}$ & .699 & \multirow{4}{*}{$\begin{array}{c}0.84 \\
8\end{array}$} & .753 & \\
\hline & $\mathrm{y}_{22}$ & .681 & & .853 & \\
\hline & $\mathrm{y}_{23}$ & .686 & & .836 & \\
\hline & $\mathrm{y}_{24}$ & .699 & & .764 & \\
\hline \multirow{5}{*}{$\begin{array}{c}\text { digital } \\
\text { innovation } \\
\text { performance } \\
\left(\mathrm{Y}_{3}\right)\end{array}$} & $\mathrm{y}_{31}$ & .753 & \multirow{5}{*}{$\begin{array}{c}0.91 \\
8\end{array}$} & .841 & \multirow{5}{*}{.896} \\
\hline & $\mathrm{y}_{32}$ & .787 & & .865 & \\
\hline & $\mathrm{y}_{33}$ & .791 & & .869 & \\
\hline & $\mathrm{y}_{34}$ & .810 & & .883 & \\
\hline & $\mathrm{y}_{35}$ & .822 & & .891 & \\
\hline
\end{tabular}

\section{EXPERIMENTAL ANALYSIS}

\subsection{Model Construction}

In this paper, AMOS 24.0 software is used to analyze the research model. For the hypothesis of inverted U-shaped relationship, the square term of knowledge heterogeneity and organization heterogeneity is introduced into the structural equation to test. If the path coefficient is negative, the hypothesis is valid.

Since the square terms are highly correlated with the independent variables, the residual centralization method is used to set the measurement indexes. In the initial model constructed, there are a total of 8 latent variables and 28 explicit variables (as shown in Figure 2). Among them, target heterogeneity $\left(\mathrm{X}_{1}\right)$, knowledge heterogeneity $\left(\mathrm{X}_{2}\right)$, organizational heterogeneity $\left(\mathrm{X}_{3}\right)$, knowledge heterogeneity square $\left(\mathrm{X}_{4}\right)$, and organizational heterogeneity square $\left(\mathrm{X}_{5}\right)$ are five exogenous latent variables, and interaction frequency $\left(\mathrm{Y}_{1}\right)$, cooperation quality $\left(\mathrm{Y}_{2}\right)$, and digital innovation performance $\left(\mathrm{Y}_{3}\right)$ are three endogenous latent variables. Due to certain errors in the measurement of questionnaire items, it is difficult to match the model completely. Therefore, error variables need to be introduced into the model to ensure that the verification process of model can be established. Therefore, in addition to explicit and latent variables, there are 28 error variables of explicit variables e1-e22 and e26e31 and 3 error variables of endogenous latent variables e23-e25 in the model. The default value of path coefficient is 1 .

The model mainly includes two kinds of equations: measurement equation and structural equation. According to the relationship between latent and explicit variables in the model, the measurement equation is expressed in the following form:

$$
\begin{gathered}
x=\alpha_{x} \mu+e_{x} \\
y=\alpha_{y} \lambda+e_{y}
\end{gathered}
$$

In the above, Equation (5-1) is an exogenous variable equation, and Equation (5-2) is an endogenous variable equation, where y represents an endogenous explicit variable and $\mathrm{x}$ represents an exogenous explicit variable. $\lambda$ denotes endogenous latent variables $\left(\mathrm{Y}_{1}, \mathrm{Y}_{2}, \mathrm{Y}_{3}\right), \mu$ denotes exogenous latent variables $\left(\mathrm{X}_{1}, \mathrm{X}_{2}, \mathrm{X}_{3}, \mathrm{X}_{4}, \mathrm{X}_{5}\right)$; The matrix $\alpha_{\mathrm{y}}$ and $\alpha_{\mathrm{x}}$ are respectively the coefficient matrices of the strength of the relationship between $y$ and $\mathrm{x}, e_{y}$ and $e_{x}$ represent the measurement errors of $\mathrm{y}$ and $\mathrm{x}$ respectively.

According to the two variable equations, the specific expression of the variable relation equation can be obtained:

$$
\left[\begin{array}{l}
x_{11} \\
x_{12} \\
x_{13} \\
x_{14} \\
x_{21} \\
x_{22} \\
x_{23} \\
x_{31} \\
x_{32} \\
x_{33} \\
x_{41} \\
x_{42} \\
x_{43} \\
x_{51} \\
x_{52} \\
x_{53}
\end{array}\right]=\left[\begin{array}{ccccc}
\gamma_{11} & 0 & 0 & 0 & 0 \\
\gamma_{12} & 0 & 0 & 0 & 0 \\
\gamma_{13} & 0 & 0 & 0 & 0 \\
\gamma_{14} & 0 & 0 & 0 & 0 \\
0 & \gamma_{21} & 0 & 0 & 0 \\
0 & \gamma_{22} & 0 & 0 & 0 \\
0 & \gamma_{23} & 0 & 0 & 0 \\
0 & 0 & \gamma_{31} & 0 & 0 \\
0 & 0 & \gamma_{32} & 0 & 0 \\
0 & 0 & \gamma_{33} & 0 & 0 \\
0 & 0 & 0 & \gamma_{41} & 0 \\
0 & 0 & 0 & \gamma_{42} & 0 \\
0 & 0 & 0 & \gamma_{43} & 0 \\
0 & 0 & 0 & 0 & \gamma_{51} \\
0 & 0 & 0 & 0 & \gamma_{52} \\
0 & 0 & 0 & 0 & \gamma_{53}
\end{array}\right]\left[\begin{array}{l}
X_{1} \\
X_{2} \\
X_{3} \\
X_{4} \\
X_{5}
\end{array}\right]+\left[\begin{array}{l}
e_{1} \\
e_{2} \\
e_{3} \\
e_{4} \\
e_{5} \\
e_{6} \\
e_{7} \\
e_{8} \\
e_{9} \\
e_{10} \\
e_{26} \\
e_{27} \\
e_{28} \\
e_{29} \\
e_{30} \\
e_{31}
\end{array}\right]
$$




$$
\left[\begin{array}{l}
y_{11} \\
y_{12} \\
y_{13} \\
y_{21} \\
y_{22} \\
y_{23} \\
y_{24} \\
y_{31} \\
y_{32} \\
y_{33} \\
y_{34} \\
y_{35}
\end{array}\right]=\left[\begin{array}{ccc}
\theta_{11} & 0 & 0 \\
\theta_{12} & 0 & 0 \\
\theta_{13} & 0 & 0 \\
0 & \theta_{21} & 0 \\
0 & \theta_{22} & 0 \\
0 & \theta_{23} & 0 \\
0 & \theta_{24} & 0 \\
0 & 0 & \theta_{31} \\
0 & 0 & \theta_{32} \\
0 & 0 & \theta_{33} \\
0 & 0 & \theta_{34} \\
0 & 0 & \theta_{35}
\end{array}\right]\left[\begin{array}{l}
Y_{1} \\
Y_{2} \\
Y_{3}
\end{array}\right]+\left[\begin{array}{l}
e_{16} \\
e_{17} \\
e_{18} \\
e_{19} \\
e_{20} \\
e_{21} \\
e_{22} \\
e_{11} \\
e_{12} \\
e_{13} \\
e_{14} \\
e_{15}
\end{array}\right]
$$

Among them, Equation (5-3) is the exogenous variable equation, and (5-4) is the endogenous variable equation. $x_{i j}$ represents the $j$ th explicit variable of the latent variable $X_{i} . y_{i j}$ represents the $j$ th explicit variable of the latent variable $Y_{i} . \gamma_{i j}$ represents the relation coefficient of the $j$ th explicit variable of $X_{i}$, and $\theta_{i j}$ represents the relation coefficient of the $j$ th explicit variable of $Y_{i}$.

According to the relationship among latent variables in the model, the structural equation of latent variables in the influence of subject heterogeneity and cooperation intensity on digital innovation performance is expressed in the following form:

$$
\left[\begin{array}{l}
Y_{1} \\
Y_{2} \\
Y_{3}
\end{array}\right]=\left[\begin{array}{ccc}
\lambda_{y 13} & 0 & 0 \\
0 & \lambda_{y 23} & 0 \\
0 & 0 & 0
\end{array}\right]\left[\begin{array}{l}
Y_{1} \\
Y_{2} \\
Y_{3}
\end{array}\right]+\left[\begin{array}{ccc}
\lambda_{x 13} & 0 & 0 \\
0 & \lambda_{x 43} & 0 \\
0 & 0 & \lambda_{x 53}
\end{array}\right]\left[\begin{array}{l}
X_{1} \\
X_{4} \\
X_{5}
\end{array}\right]+\left[\begin{array}{l}
e_{23} \\
e_{25} \\
e_{24}
\end{array}\right]
$$

$\lambda_{y i j}$ represents the path coefficient of variable $Y_{i}$ to variable $Y_{j}, \lambda_{x i j}$ represents the path coefficient of variable $X_{i}$ to variable $X_{j}$, and $e$ represents the error term.

According to the structural equation, the corresponding path and variable data were input into AMOS24.0 software to obtain the initial structural equation model, as shown in the figure below:

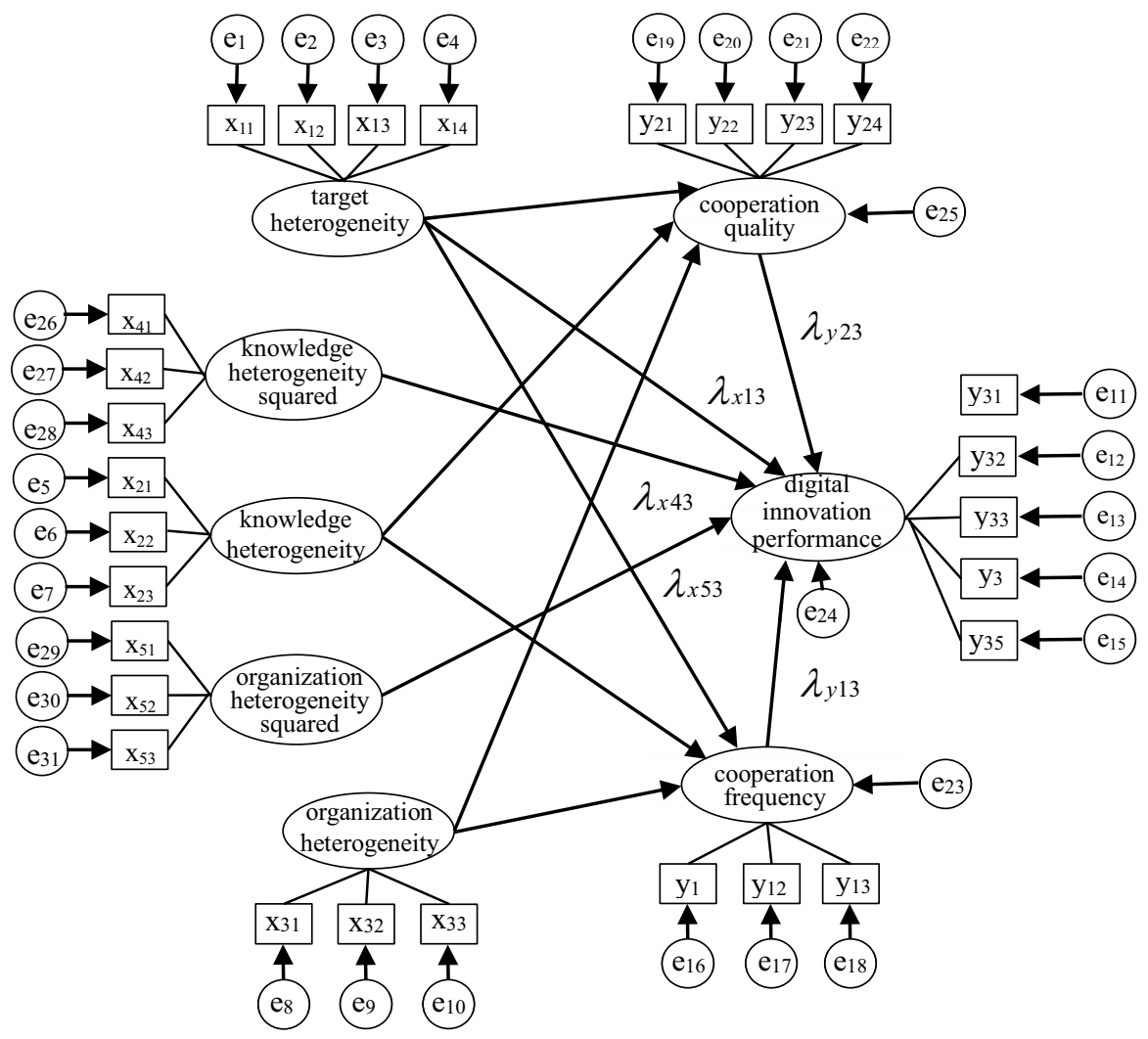

Figure 2 research model

\subsection{Results}

\subsubsection{Model Fit Summary}

In order to improve the fitting degree of the model, the model needs to be modified in combination with the modified index MI after calculation. After checking and correcting the relationship of error term between e 3 and e31 (9.038) and between e9 and e30 (7.720) within variables to reduce the deviation of fitting step by step. In the end, the results were obtained. In general, most of the fitting indicators were in a good range except NFI, which was slightly lower than the good standard, indicating that the data fitting effect was good.

\subsubsection{Path Coefficient of Model}

From the path coefficient of the model, due to the "cooperation frequency $<$ knowledge heterogeneity", "interaction frequency <Organizational heterogeneity", "cooperation quality <knowledge heterogeneity "three paths of significance level are greater than 0.05 . So we remove these three paths respectively and the resulting 
model is the final result. According to the result of path coefficient and significance level (table 4), whether the revised all paths through the test of significance $(\mathrm{P} \leq 0.05)$, we can get the relationship between the variables.

For the variables of linear relationship, the path coefficients of target heterogeneity on interaction frequency $(-0.856)$, cooperation quality $(-0.725)$ and digital innovation performance $(-0.252)$ are all negative, so there are negative correlations. Target heterogeneity has a certain negative impact on digital cooperation, and enterprises should try to minimize the goal difference of partners in cooperation. Knowledge heterogeneity has no significant correlation with interaction frequency and cooperation quality, indicating that these two variables have almost no mediating effect on knowledge heterogeneity and digital innovation efficiency. The path coefficient of organization heterogeneity on cooperation quality $(-0.353)$ is negative, showing a negative correlation, which is consistent with the hypothesis, indicating that the increase of organization heterogeneity will indeed lead to a certain increase in risk and cost. However, organization heterogeneity has no significant effect on interaction frequency and digital innovation performance, indicating that interaction frequency has no mediating effect on organization heterogeneity and digital innovation performance. The path coefficients of interaction frequency $(0.150)$ and cooperation quality (0.297) on digital innovation performance are both positive, indicating that they have a positive influence relationship, which is consistent with the hypothesis. The increase of cooperation intensity has a positive effect on digital innovation performance.

For the variables of nonlinear relationship, the path coefficients of digital innovation performance, knowledge heterogeneity square term $(-0.246)$ and organization heterogeneity square term $(-0.093)$ are both negative, so it can be judged that there is a nonlinear inverted U-shaped relationship between them, which is consistent with the hypothesis:

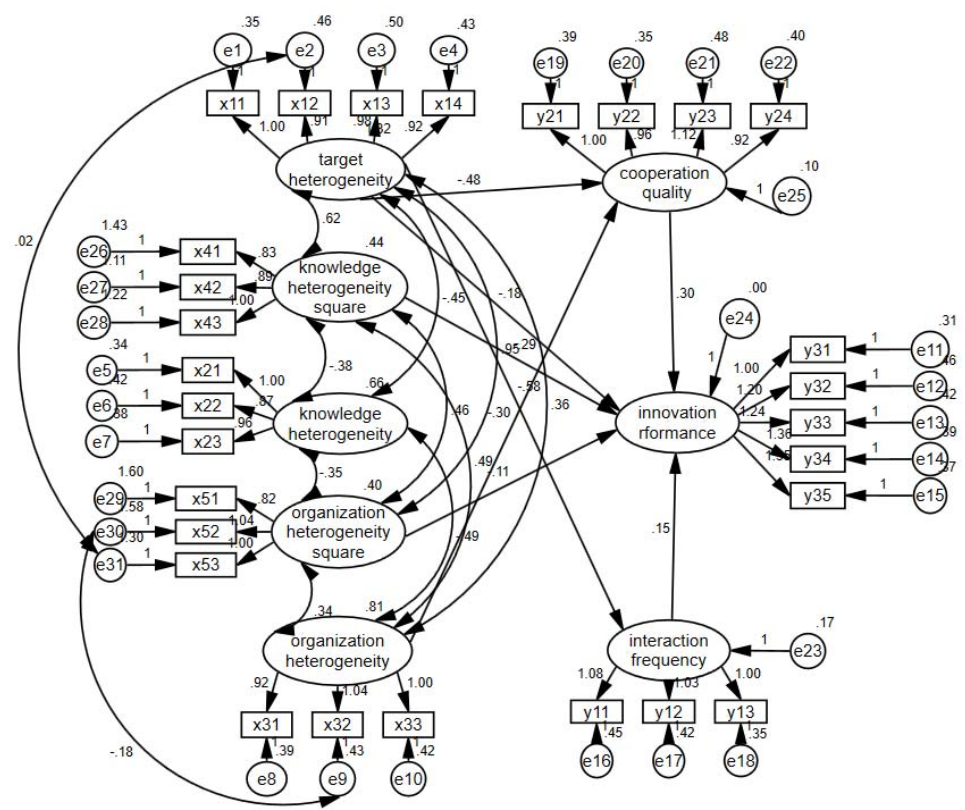

Figure 3 The modified model

Table 4 The modified results

\begin{tabular}{|c|c|c|c|c|c|c|}
\hline \multicolumn{4}{|c|}{ path } & $\begin{array}{c}\text { Standardized path } \\
\text { coefficients }\end{array}$ & $\begin{array}{c}\text { path } \\
\text { coefficients }\end{array}$ & $\mathrm{P}$ \\
\hline interaction frequency & $<$ & \multicolumn{2}{|l|}{ target heterogeneity } & -.856 & -.684 & $* * *$ \\
\hline cooperation quality & $<$ & \multicolumn{2}{|l|}{ target heterogeneity } & -.725 & -.480 & $* * *$ \\
\hline cooperation quality & $<$ & \multicolumn{2}{|c|}{ organization heterogeneity } & -.353 & -.274 & $* * *$ \\
\hline innovation performance & $<$ & \multicolumn{2}{|l|}{ target heterogeneity } & -.252 & -.186 & .008 \\
\hline innovation performance & $<$ & \multicolumn{2}{|c|}{ knowledge heterogeneity square } & -.246 & -.289 & .005 \\
\hline innovation performance & $<$ & \multicolumn{2}{|c|}{ organization heterogeneity square } & -.093 & -.113 & .007 \\
\hline innovation performance & $<$ & \multicolumn{2}{|l|}{ interaction frequency } & .150 & .139 & .028 \\
\hline innovation performance & $<$ & \multicolumn{2}{|l|}{ cooperation quality } & .297 & .331 & .002 \\
\hline$\chi^{2}$ & $\frac{1}{540.8631}$ & NFI & .877 & IFI & \multicolumn{2}{|c|}{.948} \\
\hline $\mathrm{df}$ & 330 & TLI & .940 & CFI & \multicolumn{2}{|c|}{.948} \\
\hline$\chi^{2} / \mathrm{df}$ & 1.639 & RMSEA & .055 & & \\
\hline
\end{tabular}




\subsubsection{Mediating Effect Results}

Through the above path analysis results, it can be seen that there may be mediating effects of interaction frequency and cooperation quality between target heterogeneity and digital innovation performance, and there may be mediating effects of cooperation quality between organizational heterogeneity and digital innovation performance. Therefore, we need to test their mediating effects through analysis. In this paper, Bootstrap method Is used to test the mediating effect, and repeated sampling method with retraction is used to construct the confidence interval. The mediating effect between variables was determined by whether 0 was included between the upper and lower limits. If 0 was not included, it would have a mediating effect.
As can be seen from Table 5, the indirect effect and total effect mediating effect of path"target heterogeneity>interaction frequency>innovation performance " and "organization heterogeneity $>$ cooperation quality $>$ innovation performance" are both significant, while the direct effect is not significant. These results indicate that interaction frequency plays a complete mediating role in the impact of target heterogeneity on digital innovation performance, and cooperation quality plays a complete mediating role in the impact of organizational heterogeneity on digital innovation performance. In addition, it can be seen from the negative value of all the point estimates that the negative impact of subject heterogeneity on the digital innovation performance mainly comes from its negative impact on the intervening variable.

Table 5 Mediating effect results

\begin{tabular}{|c|c|c|c|c|}
\hline \multirow[t]{2}{*}{ effect } & \multirow[t]{2}{*}{ path } & \multicolumn{2}{|c|}{$\begin{array}{c}\text { Bootstrap }(95 \% \mathrm{CI}) \\
\text { Percentile }\end{array}$} & \multirow[t]{2}{*}{ significance } \\
\hline & & Lower & Upper & \\
\hline \multirow{3}{*}{$\begin{array}{l}\text { indirect } \\
\text { effect }\end{array}$} & target heterogeneity $>$ interaction frequency $>$ innovation performance & -0.201 & -.008 & yes \\
\hline & target heterogeneity $>$ cooperation quality $>$ innovation performance & -.420 & -.036 & yes \\
\hline & organization heterogeneity $>$ cooperation quality $>$ innovation performance & -.283 & -.021 & yes \\
\hline \multirow{3}{*}{$\begin{array}{l}\text { direct } \\
\text { effect }\end{array}$} & target heterogeneity $>$ innovation performance & -.380 & .101 & no \\
\hline & target heterogeneity $>$ innovation performance & -.665 & .191 & no \\
\hline & organizational heterogeneity $>$ innovation performance & -.343 & .017 & no \\
\hline \multirow{3}{*}{ total effect } & target heterogeneity $>$ innovation performance & -.608 & -.271 & yes \\
\hline & target heterogeneity $>$ innovation performance & -.665 & .191 & no \\
\hline & organization heterogeneity $>$ innovation performance & -.526 & -.034 & yes \\
\hline
\end{tabular}

Table 6 Summary of the results

\begin{tabular}{c|c|c}
\hline hypotheses & Proposition & Support \\
\hline H1 & Target heterogeneity relates negatively to digital innovation performance. & Supported \\
\hline H2 & $\begin{array}{c}\text { Knowledge heterogeneity has an inverted U-shaped relationship with digital innovation } \\
\text { performance. }\end{array}$ & Supported \\
\hline H3 & $\begin{array}{c}\text { Organization heterogeneity has an inverted U-shaped relationship with digital innovation } \\
\text { performance. }\end{array}$ & Supported \\
\hline H4 & Target heterogeneity relates positively to interaction frequency. & Not Supported \\
\hline H5 & Knowledge heterogeneity relates positively to interaction frequency. & Not Supported \\
\hline H6 & Organization heterogeneity relates positively to interaction frequency. & Not Supported \\
\hline H7 & Interaction frequency relates positively to digital innovation performance. & Supported \\
\hline H8 & Target heterogeneity relates negatively to cooperation quality. & Supported \\
\hline H9 & Knowledge heterogeneity relates positively to cooperation quality. & Not Supported \\
\hline H10 & Organization heterogeneity relates positively to cooperation quality. & Supported \\
\hline H11 & Cooperation quality relates positively to digital innovation performance. & Supported \\
\hline
\end{tabular}

\section{DIGITAL INNOVATION \\ PERFORMANCE OF MANUFACTURING ENTERPRISES IMPROVEMENT STRATEGIES}

\subsection{Strategies Based on the Perspective of Subject Heterogeneity}

Through the empirical research, it is found that the subject heterogeneity in manufacturing digital innovation does have a certain influence on innovation performance, and most of the influence is negative. Therefore, the enterprises in manufacturing value chain should carefully choose their partners, carry out digital cooperation according to their own situation and needs, improve the collaborative innovation ability among various subjects, give play to their respective capabilities and advantages, and realize the complementarity of resources. According to the three dimensions of subject heterogeneity, the following suggestions are put forward:

\subsubsection{Choose digital partners wisely.}

According to the research results, target heterogeneity has 
a negative impact on digital innovation performance (0.252). Therefore, before cooperation, enterprise managers should, on the one hand, screen and evaluate the information of pre-cooperation enterprises in all aspects, and give priority to the partners with small differences in enterprise targets, easy compatibility, optimal knowledge potential difference and similar organizational structure, so as to ensure that enterprises can select cooperative innovation subjects purposely. On the other hand, the cooperative projects should be strictly evaluated and reviewed to determine whether the key of cooperation, digital technology development points and cooperation objectives are consistent, and to analyze whether the optimal complementary matching can be achieved.

\subsubsection{Enhance the knowledge synergy with the innovation subjects.}

The results show that there is an inverted U-shaped relationship between knowledge heterogeneity and digital innovation performance $(-0.246)$, which indicates that only when the enterprise has an appropriate knowledge potential difference with partners, that is, it can enhance the digital innovation performance by enhancing the knowledge synergy with the cooperative entities. Enterprises should continuously improve their own digital technology and knowledge reserve, conduct reasonable resource complementarity in cooperation, and accelerate the integration and diffusion of technology and knowledge among all links of the value chain. On the one hand, the enterprise should improve the internal digital innovation vitality, take the learning of digital technology and the adoption of emerging digital innovation achievements as one of the performance appraisal standards, realize the willingness of all staff to digital construction, and accelerate the digital transformation of the enterprise. On the other hand, enterprises should realize the integrated application of industrial data resources with the help of value chain, strengthen the application research of digital technology in enterprise business activities, and use digital platform or industrial Internet to obtain real-time data of users, so as to obtain the latest market knowledge and resources.

\subsubsection{Make full use of the value chain of manufacturing industry for coordinated development, and give play to the leading role of digital transformation in large-scale enterprises.}

There is an inverted U-shaped relationship between organizational heterogeneity and digital innovation performance (-0.093), and enterprises should seize the opportunity to utilize the value chain for collaborative development. Due to the high initial cost of enterprise digital transformation, so large enterprises can be more proactive in digital transformation, and using the existing advantages to carry out the collaborative innovation throughout resource sharing, risk-sharing on the value chain. For example, estabilishing a digital platform of "cloud" can help to realize business data flow of the value chain, the digital technology will be shared in the platfor, and support for collaborative manufacturing based on these data and technology. Small and medium-sized enterprises should actively seek cooperation with enterprises of the leading level in digital transformation in their industry, by joining the Internet platform, industry innovation platform. In this way, enterprises can quickly acquire the latest digital technology and knowledge in the industry in the process of cooperation, reduce the uncertainty in the transformation process, disperse risks and help enterprises realize digital transformation.

\subsection{Strategies Based on the Perspective of Cooperation Intensity}

It can be seen from the research results that the improvement of cooperation intensity has a positive impact on digital innovation performance (interaction frequency is 0.150 , and cooperation quality is 0.297 ). In addition, it can be seen that the negative effect of target heterogeneity on digital innovation performance is entirely from the mediating role of interaction frequency, the negative impact of the inverted u-shaped relation betewwn organization heterogeneity and digital innovation performance mainly comes from the mediating role of cooperation quality. So it is conducive to improve the innovation performance by keeping good interaction frequency and high quality in digital cooperation. Therefore, the following suggestions are put forward for digital innovation to improve cooperation quality:

\subsubsection{Enhance the cooperative innovation effect between enterprises by maintaining high frequency of communication and interaction in cooperation.}

Collaborative innovation among enterprises is inseparable from daily and close communication and exchange. An effective communication and management platform should be established between enterprises and partners to enhance the willingness to share knowledge and reduce the misunderstanding in the process of knowledge decoding. On the one hand, the enterprise can establish a fixed communication team to conduct formal communication and visit each other on a regular basis, so as to understand the cooperation process of both sides and supervise the quality of information transmission. On the other hand, both sides can conduct informal communication through social platforms to enhance their feelings and the degree of trust in cooperation.

\subsubsection{Build a stable network relationship of cooperation.}

Enterprises should establish a good cooperative relationship with partners, increase the "embeddedness" of corporate social network, and build a stable collaborative innovation network. In the process of cooperation, a corresponding mechanism can be established to maintain the trust among partners. First, the reputation mechanism can be used to reduce information asymmetry in cooperation and prevent opportunism and free-riding stealing digital technology. Second, establish reasonable 
profit distribution mechanism and strengthen contract management. After the cooperation, we should establish appropriate long-term cooperation based on innovation. It is better to use part of resources to focus on a few partner relationship maintenance if necessary, through relationship commitment to win the trust of partners, to improve the stability of the network of cooperation, establish a close cooperative relationship between the different subjects, realize all kinds of digital resources sharing, the formation of collaborative innovation together in the manufacturing value chain.

This study shows that the value chain in manufacturing digital innovation, the innovation subject heterogeneity and cooperative behavior has impact on digital innovation performance in the value chain of manufacturing digital innovation. The effective integration and interaction of heterogeneous subjects in the cooperation of digital innovation helps to realize the digital collaborative development on the value chain, to promote the value cocreation between digital innovation subjects and create synergy benefit maximization.

\section{CONCLUSION}

The results show that target heterogeneity $(-0.353)$ has a negative effect on digital innovation performance. The knowledge heterogeneity (-0.246) and organization heterogeneity (-0.093) have an inverted U-shaped relationship with digital innovation performance. In addition, the interaction frequency $(0.135)$ and cooperation quality $(0.274)$ among the subjects of value co-creation have a positive effect on digital innovation performance. Therefore, the enterprises in manufacturing value chain should carefully choose their partners, carry out digital cooperation according to their own situation and needs, improve the collaborative innovation ability among various subjects, give play to their respective capabilities and advantages, and realize the complementarity of resources.

\section{Acknowledgement}

*This work was supported in part by the National Natural Science Foundation of China (71972060)

\section{References}

1. Dawei Song, Wen Guo. Development of China's Service-oriented Manufacturing and Its Outlook into 14th Five-Year Plan[J]. Bulletin of Chinese Academy of Sciences, 2020, 35(11): 1358-1365

2. Xian Du. Research on the Mechanism of the Impact of Innovation Network Relationship Strength on Innovation Performance[D]. A Dissertation for the Degree of M. Mgt, Harbin Engineering University,2017: 7

3. Cai Wang. The Impact of the Digital Transformation on Corporation Innovation Performance[J]. Contemporary Economic Management, 2021:43

4. Yunwu Guo. Research on the Two-Dimensional
Competence and Performance of Digital Transformation of SME[D]. A Dissertation for the Degree of M. Mgt, Zhejiang university,2018: 6

5. Qing Zhou, Yanling Wang, Wei Yang. An empirical study of the impact of digital level on innovation performance-A study based on the panel data of 73 counties (districts, cities) of Zhejiang Province[J]. Science Research Management, 2020,41(7):120-129

6. Yao Jin. Research on the Relation between the Development of Information Services and the Manufacturing Technological Innovation Capabilities-Based on Mediating effect of digitization[D]. A Dissertation for the Degree of M. Mgt, Xidian University,2019:6

7. Yudong Qi, Chengwei Cai. Research on the Multiple Effects of Digitalization on the Performance of Manufacturing Enterprises and Their Mechanisms[J]. Study \& Exploration, 2020,7:108-119

8. Yishu Dai, Mengling Yan, Xiaoying Dong. The relationship between enterprise attention to policy and performance in digital innovation[J]. Studies in Science of Science,2020,38(11):2068-2076

9. Xuejiao Li. Study on the Influence of Subject Heterogeneity on cooperative Performance in Industry-University-Research Cooperation[D]. A Dissertation for the Degree of M. Mgt, Changchun University of Technology,2019:6

10. Phillips, Lawrence, T. B, Hardy. Inter-organizational collaboration and the dynamics of institutional fields[C].ournal of Management Studies,2000.37( 1): 23-44

11. Beckman, C. M., Haunschild, P. R. Network learning: The effects of partners' heterogeneity of experience on corporate acquisitions[J]. Admini-strative Science Quarterly, 2002, 47(1):92-124.

12. Liang Liang. The Impact of Partner Organization Heterogeneity On Innovation Performance In Open Innovation[D]. A Dissertation for the Degree of $\mathrm{M}$. Mgt, Zhejiang university,2015:6

13. Liufang Yu, Jidong Yin, Shuiping Xu. Hetero-geneity Characteristics of Subject and Relationship Risk in Innovation Alliances under Supply-Side Reform[J]. Science \& Techology Progress and Policy, 2017, 34(5): 6-13

14. Xignhua Dang, Yali Li, Wei Zhang, The effect of resource heterogeneity and the core enterprise formed in technological innovation network[J]. Studies in Science of Science, 2010, 20(2):299-306

15. Yuanyuan Jiao. The Mechanism of Actors' Heterogeneity Affecting University-IndustryCooperative Relationship Quality[D]. Doctoral Dissertation, Jilin University, 2017:11

16. Yong Dai, Mingfu Hu. The effect of industryuniversity-research partner heterogeneity on collaborative innovation performance: From the perspective of organizational learning $[\mathrm{J}]$. Higher Education Exploration,2016,1:5-11

17. Guanju Chen, Hui Zhang. Relationship Among 
Organizational Heterogeneity, Interaction Intensity and Cooperative Innovation Performance[J]. Forum on Science and Technology in China, 2020,2:28-35

18. Beibei Zhao. Research on The Influence of The Heterogeneity of Key Common Technological Innovation Subjests on Enterprises' Technological Innovation Performance [D]. A Dissertation for the Degree of M. Mgt, University of South China, 2019:5

19. Yunjun Ma. The Evaluation of China's Large and Medium-sized Manufacturing Innovation Efficiency Based on Innovation Value Chain[D]. Doctoral Dissertation, Liaoning University, 2013:12

20. Jiang Yu, Qingshi Meng, Yue Zhang, etc. Digital innovation: Exploration and enlightenment of the new perspective of innovation research [J]. Studies in Science of Science, 2017,35(7):1103-1111

21. $\mathrm{Hu}$ Yue, Zongyi Zhang, Huainian Zhu. Innovation Partner Heterogeneity, Dual Organization Lear-ning and Open Innovation Performance[J]. Chinese Journal of Management, 2018,15(1):48-56

22. Mikalef, P., Pateli, A. Information TechnologyEnabled Dynamic Capabilities and their Indirect Effect On Competitive Performance: Findings From PLS-SEM and fs QCA[J]. Journal of Business Research, Vol, 70, No.1, 2017.

23. Bruyaka O. Alliance Partner Diversity and Biotech Firms' Exit. Differing Effects on Dissolution versus Divestment[M]. Paper presented at the Academy of Management Proceedings,2008.

24. Zhanyun Wang. The Role of Goal Incongruence, Information Sharing Behavior of Emergency Partnership-The Moderator Role of Task Uncertainty [D]. A Dissertation for the Degree of M. Mgt, Wuhan Textile University,2015:5

25. Qiang Cheng. A Study on The Impact of EnterpriseUniversity-Institude Collaboration Heterogeneity on Industry Collaboration Performance[D]. A Dissertation for the Degree of M. Mgt, South China University of Technology, 2015:6

26. Lisheng Wang. The effect of social capital and absorptive capacity on knowledge acquisition and innovation performance [D]. Doctoral Dissertation, Zhejiang University,2007:10

27. Jing Song, Juhong Chen, Yonglei Sun. Impact of Network Competence on Cooperative Innovation Performance in Different Regional Culture[J]. Management Review, 2015, 27(2): 35-42+119

28. Yongqiang Ma, Yuanyuan Lu. Firm heterogeneity, internal control and corporate innovation performance $[\mathrm{J}]$. Science Research Management, 2019, 40(5): 134-144 